Revue d'histoire du XIXe siècle

Société d'histoire de la révolution de 1848 et des

révolutions du XIXe siècle

$46 \mid 2013$

L'espace du politique en Allemagne au XIXe siècle

Aurélien Lignereux, L'Empire des Français, 1799-1815. Histoire de la France contemporaine, vol. 1

Collection L'Univers historique, Paris, Le Seuil, 2012, 417 p. ISBN :

978-2-02-100083-2. 25 euros

Natalie Petiteau

\title{
CpenEdition
}

Édition électronique

URL : http://journals.openedition.org/rh19/4459

DOI : $10.4000 /$ rh 19.4459

ISSN : $1777-5329$

Éditeur

La Société de 1848

Édition imprimée

Date de publication : 1 juin 2013

Pagination : 193-195

ISSN : 1265-1354

Référence électronique

Natalie Petiteau, «Aurélien Lignereux, L'Empire des Français, 1799-1815. Histoire de la France

contemporaine, vol. 1 », Revue d'histoire du XIXe siècle [En ligne], 46 | 2013, mis en ligne le 13 janvier

2014, consulté le 22 septembre 2020. URL : http://journals.openedition.org/rh19/4459; DOI : https:// doi.org/10.4000/rh19.4459

Ce document a été généré automatiquement le 22 septembre 2020

Tous droits réservés 


\section{Aurélien Lignereux, L'Empire des Français, 1799-1815. Histoire de la France contemporaine, vol. 1}

Collection L'Univers historique, Paris, Le Seuil, 2012, 417 p. ISBN :

978-2-02-100083-2. 25 euros

\section{Natalie Petiteau}

\section{RÉFÉRENCE}

Aurélien LIGNEREUX, L'Empire des Français, 1799-1815. Histoire de la France contemporaine, vol. 1, collection L'Univers historique, Paris, Le Seuil, 2012, 417 p. ISBN :

978-2-02-100083-2. 25 euros.

1 L'auteur de ces lignes, qui a appelé de ses vœux à un renouvellement de l'histoire napoléonienne par un livre paru en 1999, puis par un colloque organisé à Avignon en 2000, ne peut que se réjouir très vivement de la publication de ce bel ouvrage. Cela faisait plusieurs années qu'elle avait le sentiment d'être entendue, par plusieurs jeunes historiens en matière d'anthropologie des guerres de l'Empire, et par Aurélien Lignereux en matière du rapport des Français à l'Empire. Que ce même Aurélien Lignereux signe cette synthèse ne peut qu'ajouter à sa satisfaction de n'avoir pas écrit et travaillé pour rien!

2 Car cette synthèse menée tambour battant d'un bout à l'autre du volume est réjouissante. Par son style tout d'abord, toujours élégant et cultivant l'art des belles formules. Presque trop parfois... la beauté du style est parfois préférée à la clarté du propos. Reste que ce livre est très bien construit et très dense. Aurélien Lignereux est pourtant hélas obligé de partir d'un constat peu différent de celui que l'on pouvait faire il y a douze ans : "La richesse du patrimoine des études napoléoniennes dissimule mal la pauvreté des problématiques » (p. 9). L'auteur n'en a pas moins raison de relever que certaines pistes ont tout de même été suivies depuis le colloque d'Avignon, même s'il 
est réducteur de dire qu'elles n'auraient concerné que la propagande, l'administration et la guerre. L'ouvrage s'inscrit dans une collection qui vise à construire « une histoire de France déployée vers l'extérieur » (p.11), et en la matière Aurélien Lignereux relève courageusement le défi, notamment en insistant sur la question qui lui est chère de l'identité française.

Une première partie, sur "Les moments napoléoniens ", place dans une perspective cavalière les années 1799-1812 pour étudier comment elles finissent la Révolution, puis comment elles conduisent à sortir de la République et enfin comment on y construit l'Empire. On suit parfaitement l'auteur quand il qualifie Bonaparte, en novembre 1799, d'« homme d'une situation » (p. 19), dans un contexte où la chute du Directoire n'avait en réalité rien d'inexorable. Bonaparte sait en tout cas faire face à la situation des lendemains de Brumaire en s'entourant de bons collaborateurs et en se faisant pacificateur: l'auteur montre bien l'œuvre d'apaisement et de reconstruction, sans oublier de faire état des persistantes oppositions intérieures. Notons la belle maitrise avec laquelle Aurélien Lignereux décrit la recomposition de la carte de l'Europe. Mais l'on s'étonne qu'il n'insiste guère sur le fait que, pour Napoléon, construire l'Empire, c'est aussi construire un Empire face à celui de la Grande-Bretagne. Il faut ne pas oublier que l'histoire des années 1799-1815 est avant tout celle de la lutte de deux impérialismes. La guerre met face à face deux volontés au minimum...

Une deuxième partie fait une pause chronologique pour envisager «État napoléonien et état de la société ", par une approche d'en haut tout d'abord, "Gouverner la société », puis d'en bas, "De l'Empire voulu à l'Empire vécu ", puis à la Goubert, "Napoléon et 40 millions de Français ». Aurélien Lignereux met à profit les nouveaux travaux sur le Conseil d'État ou le ministère de l'Intérieur pour montrer tant les continuités que les inventions. Il note également les continuités lignagères dans les services des préfectures et livre une bonne synthèse sur le rôle des préfets, des souspréfets et des maires, non sans analyser les appartenances sociales des individus jugés dignes d'encadrer la société. On est en revanche un peu déçu quand l'auteur aborde la fusion des élites par des biais un peu réducteurs. C'était du côté de la Légion d'honneur et de la noblesse impériale qu'il fallait aller voir, sans négliger bien sûr les listes de notabilités. Mais l'auteur évoque avec raison le Conseil des manufactures, les Chambres de commerce, la structuration des professions libérales. Bref il montre bien que gouverner la société passe par une recomposition sociale soigneusement contrôlée. L'analyse du Code civil est clairement menée. Les processus de contrôle des esprits sont également bien présentés. On apprécie que les espaces de refus ne soient pas oubliés, tant ils sont finalement nombreux. En examinant les rapports entre Napoléon et 40 millions de Français, l'auteur montre les progrès de la démographie, la portée des grands travaux, la place des industries de luxe, la modernisation des industries textiles, les voies de maintien de la paix sociale, la place du travail de la terre comme socle de l'économie française. Les pages qu'il livre sur la situation économique sont une bonne synthèse des apports des travaux récents.

5 La troisième partie est la plus neuve, qui envisage les Français des temps impériaux sous l'angle de la génération. Génération du feu tout d'abord, comprenant 14 millions de nouveaux Français. "Génération impérialiste » qui a un nouveau rapport à l'identité française. Mais les pages sur la guerre ne sont pas celles où excelle notre auteur, qui se rattrape cependant très vite avec ses développements sur ces 14 millions de nouveaux Français. Aux expressions confuses du chapitre précédent succèdent les bonheurs 
d'écriture de celui-ci, qui invite notamment à redoubler de prudence quant à l'éventuelle naissance d'un espace économique élargi aux annexions et qui souligne comment l'histoire de ces départements révèle l'absence de régime totalitaire. C'est enfin avec raison qu'Aurélien Lignereux pose la question de l'identité française, question difficile à résoudre : qu'est-ce alors qu'être Français? En tout état de cause, l'unité n'est pas acquise, même si les Français sont alors unis dans la soumission aux mêmes codes.

6 La quatrième partie revient à la chronologie pour raconter les "Fins d'Empire ", de 1812 à 1814. Elle étudie comment meurt un Empire. Elle revient enfin sur les Cent Jours, en se demandant habilement s'il ne faut pas y voir « un premier Second Empire "... L'auteur analyse par ailleurs la façon dont se joue le sort de l'Empire et il insiste avec raison sur la diversité des attitudes et sur les voies de décomposition du pouvoir central. Avec raison également il prend en considération ce qui a miné l'Empire de l'intérieur, sujet essentiel pour la compréhension de la période. Finalement, conclutil, l'empreinte napoléonienne n'est profonde que là où la société est apte à s'approprier les changements. Un très beau livre donc, qui invite à son tour à la poursuite des recherches sur la période. 